\title{
Avanços e retrocessos ao sentido de capacidade legal: panorama prospectivo sobre decisões existenciais de pessoas com deficiência
}

\author{
Advances and regress on the meaning of legal capacity: a prospective overview \\ of persons with disabilities' existential decisions
}

\author{
Jacqueline Lopes Pereira* \\ Ana Carla Harmatiuk Matos**
}

\section{Resumo}

A Convenção de Nova lorque sobre os Direitos das Pessoas com Deficiência é marco legal para o reconhecimento de direitos das pessoas com deficiência, porém não é divisor de águas que mudará a vivência desse grupo vulnerável. $A$ leitura de uma capacidade legal conglobante pretende revisar paradigmas do regime clássico das incapacidades. Partese da necessidade de examinar o ordenamento jurídico brasileiro sob a disciplina promulgada pelo tratado internacional e pelo Estatuto da Pessoa com Deficiência. O estudo explora os sentidos formal, substancial e prospectivo de direitos clamados por pessoas com deficiência e sua efetividade no contexto brasileiro. Sob o método dedutivo em análise teórica feita por revisão bibliográfica da doutrina atual, o artigo se divide em três seções. Na primeira, revisa-se criticamente o regime clássico das incapacidades, em que imperou a "perspectiva de substituição da vontade" para a proteção patrimonial, com efeito de também eclipsar as preferências em decisões existenciais. Em segunda seção, discorre-se sobre o conceito conglobante de capacidade legal da Convenção e a ênfase dada pelo texto normativo à autonomia em escolhas existenciais, dentre as quais está a decisão de com quem viver em conjugalidade. No terceiro item, investiga-se o direito à escolha de com quem se casar e as fissuras que persistem no cenário doutrinário e legislativo, e que obstam o reconhecimento do exercício de liberdades por essas pessoas. Conclui-se que o sentido formal de se positivar direitos das pessoas com deficiência é apenas um primeiro passo para a concretização de proteção de seus direitos.

Palavras-chave: Pessoas com deficiência. Direitos humanos. Capacidade legal. Direitos da personalidade.

\section{Abstract}

New York Convention on the Rights of Persons with Disabilities is a legal framework to advance the recognition of persons with disabilities' rights, but it is not a watershed that will change this vulnerable group's experience. The conglobating legal capacity intends to review paradigms of the civil capacity's classic regime. This paper studies the Brazilian legal system since the changes promulgated by the International Treaty and by the Statute of Persons with Disabilities. Thus, the study explores the formal, substantial and prospective meanings of rights claimed by people with disabilities and their effectiveness in the Brazilian context. By deductive method and theoretical analyzis with literature review, the paper is divided in three sections. On the first one, the paper critically examines the classic regime of civil capacity in Brazil, where the "outcome approach" to the patrimonial protection prevailed, with effect of also eclipsing the preferences of these people to make existential choices. In the second section, the paper discuss the conglobating meaning of "legal capacity" from the UN Convention and its special emphasis on autonomy in existential choices, such as the decision of whom to live with in conjugality. The third section investigates the right to choose who to marry with and the fissures that persist in academical and legislative scene that hinder the recognition of these people's exercise of freedom. The conclusion is that the formal sense of affirming the rights of people with disabilities is only a first step towards materializing the protection of their rights.

Keywords: People with disabilities. Human rights. Legal Capacity. Rights of personality.

Mestranda em Relações Sociais pelo Programa de Pós-Graduação em Direito da Universidade Federal do Paraná - PPGD/UFPR, pesquisadora do Eixo de Relações Familiares do Núcleo de estudos em Direito Civil - Virada de Copérnico, e do Núcleo de Direitos Humanos e Vulnerabilidades. Especialista em Direito das Famílias e Sucessões pela Academia Brasileira de Direito Constitucional - ABDConst. Membro da Comissão de Diversidade Sexual da OAB/PR. Bolsista pelo Programa de Excelência Acadêmica (CAPES/PROEX). Pesquisadora visitante do Instituto Max Planck para Direito Comparado e Internacional Privado. Professora da Faculdade de Pinhais. Curitiba - PR - Brasil. E-mail: jacqueline.lopes10@gmail.com.

Doutora e mestra em Direito pela Universidade Federal do Paraná. Mestra em Derecho Humano pela Universidad Internacional de Andalucía. Tutora Diritto na Università di Pisa - Itália. Professora na graduação, mestrado e doutorado em Direito da Universidade Federal do Paraná. Vicecoordenadora do Programa de Pós-graduação em Direito da Universidade Federal do Paraná. Diretora Regional Sul do Instituto Brasileiro de Direito de Família. Advogada com ênfase em Direito de Família. Curitiba - PR - Brasil. E-mail: a.c.matos@uol.com.br. 


\section{Introdução}

O lema "Nada sobre nós, sem nós", consagrado pelos movimentos sociais representativos dos direitos das pessoas com deficiência alcançou patamar de auxiliar na redação da Convenção de Nova lorque. Esta, todavia, não é uma conquista que se possa qualificar como ponto final para a melhoria da sua condição de liberdade e igualdade.

A teoria crítica dos direitos humanos dá azo a essa afirmação nada confortável, que leva a questionarse o Direito como instrumento de concretização de vivências humanas com mais dignidade. ${ }^{1}$ Os "avanços" na proteção de direitos das pessoas com deficiência não são lineares, e são tensionados a todo momento por forças e interesses que laboram a favor retrocessos. Daí a justificativa para o estudo proposto: explorar os sentidos formal, substancial e prospectivo de direitos clamados por pessoas com deficiência e sua efetiva concretização.

Levando em consideração essas constatações, pretende-se analisar o estado da arte do conceito de capacidade legal, propugnado pela Convenção de Nova lorque sob o recorte do direito civil brasileiro, e o direito à escolha de com quem se casar.

Para isso, primeiramente, empreende-se exame sobre o regime clássico das incapacidades que, em sua origem, evidencia a imposição vertical de qualificações a pessoas com deficiência, psíquica ou intelectual, para a prática de atos civis, operando-se por parâmetro de substituição de suas preferências.

Em segundo momento, o artigo explora o conceito conglobante de capacidade legal e a especial ênfase dada pelo texto normativo à autonomia em escolhas existenciais, dentre as quais está a decisão de com quem viver em conjugalidade.

Por fim, verticaliza-se o direito à escolha de com quem se casar e as fissuras que persistem no plano doutrinário e legislativo de obstar o reconhecimento do exercício de liberdades por essas pessoas.

É nítido que o marco legal contribui para o avanço dessas questões, porém, faz-se imprescindível pensar nos conceitos normativos aplicados e vivenciados pelos sujeitos de "carne e osso", desprendidos de um perfil abstrato.

\section{O sentido clássico da capacidade civil no direito brasileiro para atos existenciais e suas fissuras}

A complexidade da vida concreta produz fissuras que o Direito deve encarar e intermediar em prol do desenvolvimento e proteção de direitos humanos e fundamentais. A temática da proteção e emancipação de pessoas com deficiência, psíquica ou intelectual, está dentre essas fendas.

O sistema clássico das incapacidades por vezes resultou em um ocultamento de preferências de sujeitos para decisões de âmbito existencial, como casar-se ou com quem se relacionar, resultando em quadros contemporâneos como os dos seguintes relatos colhidos pela Organização Não Governamental “Inclusão Internacional” (2015, p. 71):

El personal me impidió tener una novia; no me dejaron verla más. Las personas tratan de evitar que tengamos relaciones sexuales porque creen que no podemos asumir el cuidado de un hijo. No quieren que tengamos hijos porque no quieren más personas con discapacidad. Estoy saliendo con alguien, pero no tengo planes de casarme, no se permitiría.

Depoimentos como esse demonstram os desafios e incertezas que pessoas com deficiência enfrentam perante um paradigma substitutivo de sua vontade sustentado pelo direito civil tradicional.

\footnotetext{
“O 'direito' dos direitos humanos é, portanto, um meio - uma técnica -, entre muitos outros, na hora de garantir o resultado das lutas e interesses sociais e, como tal, não pode se afastar das ideologias e das expectativas dos que controlam seu funcionamento tanto no âmbito nacional como no âmbito internacional. Certamente, cabe um uso alternativo do jurídico que o interprete ou o aplique em função dos interesses e expectativas das maiorias sociais." (FLORES, 2009, p. 18).
} 
Isto evidencia a pouca simplicidade que envolve a proteção da escolha exercida por pessoas com deficiência. É de se ressaltar que estas são sujeitos socialmente deixados à margem da participação democrática e sua condição de dignidade deixa a desejar no contexto contemporâneo, que tanto se contrapõe às conquistas legislativas constantes de tratados internacionais e normas do direito brasileiro.

De acordo com a Organização das Nações Unidas, há aproximadamente 1 bilhão de pessoas com deficiência no mundo (ONU, 2016a, p. 71). Destas, 80\% vivem em países em desenvolvimento (ONU, 2010, p. 07), o que representa uma sobreposição de vulnerabilidades que se intensificam reciprocamente. ${ }^{2} \mathrm{Na}$ conjuntura da América Latina e Caribe, $82 \%$ das pessoas com deficiência vivem abaixo da linha da pobreza (NABERGOI; BOTINELLI, 2007). Essa vulnerabilidade é agravada se a pessoa é do gênero feminino, caso em que abusos físicos e sexuais são mais comuns, ou então se a pessoa com deficiência é uma criança em país em desenvolvimento, onde $90 \%$ não têm acesso ao direito à educação básica (ONU, 2016b).

Especificamente no Brasil, o Instituto Brasileiro de Geografia e Estatística (IBGE, 2013, p. 23) publicou dados estimando que, no ano de $2013,6,2 \%$ da população era constituída por pessoas com deficiência intelectual, física, auditiva ou visual.

Esse contingente populacional vivencia exclusões que tornam ainda mais latente a sua precarização. Judith Butler (2015, p. 46-47) afirma que a precariedade resulta do viver socialmente, todavia, a condição precária é produto do entrecruzamento de fatores políticos, sociais e econômicos:

\begin{abstract}
Vidas são, por definição, precárias: podem ser eliminadas de maneira proposital ou acidental; sua persistência não está, de modo algum, garantida. Em certo sentido, essa é uma característica de todas as vidas, e não há como pensar a vida como não precária [...]. A condição precária designa a condição politicamente induzida na qual certas populações sofrem com redes sociais e econômicas de apoio deficientes e ficam expostas de forma diferenciada às violações, à violência e à morte. Essas populações estão mais exposta a doenças, pobreza, fome, deslocamentos e violência sem nenhuma proteção.
\end{abstract}

A condição precária, ou de vulnerabilidade, constatada no caso das pessoas com deficiência foi combatida pelo direito civil clássico a partir do que se denominou de regime das incapacidades. Com a justificativa de proteção dessas pessoas, construiu-se técnica jurídica que as declarava incapazes para a prática de atos da vida civil e nomeava-Ihes uma terceira pessoa para tomar decisões sobre sua vida e administrar seus bens.

Segundo o sistema clássico, a "capacidade jurídica" tinha uma definição embasada na construção da codificação oitocentista do direito privado que, em síntese, a retratava como o "poder de ação e atributo da personalidade do sujeito de direito" (AMARAL, 2006, p. 218). Assim como em outros países de tradição Civil law, o referido conceito se dividia em capacidade de direito e capacidade de exercício.

A capacidade de direito seria o atributo de toda pessoa natural ser considerada um sujeito perante o ordenamento jurídico, enquanto a capacidade de exercício se remeteria à aptidão da pessoa exercer seus direitos por si própria.

Mesmo no sistema clássico brasileiro, não havia controvérsias quanto à detenção de capacidade de direito por pessoas com deficiência psíquica ou intelectual, todavia o direito positivo estabelecia gradações quanto à capacidade de exercício: "loucos de todo gênero" ou "surdos-mudos que não poderiam exprimir sua vontade" eram considerados "absolutamente incapazes" pelos incisos II e III do artigo $5^{\circ}$ do Código Civil brasileiro de 1916. Ou seja, após processo de interdição - pautado em uma lógica extremamente patologizadora e estruturada na visão médica ${ }^{3}$ - as pessoas assim identificadas deixariam de ter reconhecido o exercício de direitos e de deliberar sobre seus bens e sua própria vida por si.

\footnotetext{
Um exemplo dessa mútua intensificação de vulnerabilidades é a de que, de acordo com o Relatório Mundial de Pessoas com Deficiência, muitas crianças abandonam as escolas no Brasil em virtude de deficiência visual que seria evitada pelo uso de óculos na infância, porém que é um acessório cujo custo não suportado pelas famílias mais pobres (WORLD HEALTH ORGANIZATION, 2011, p. 22).

Agustina Palacíos e Javier Romañach (2008, p. 23) sintetizam as características atribuídas ao "modelo médico" de compreensão da deficiência vinculadas à ideia de inadequação ou anormalidade de uma pessoa à vida em sociedade: "El modelo médico o rehabilitador entiende que la persona con discapacidad lo es por una anomalía física, psíquica o sensorial producida por cualquier circunstancia (ya sea permanente o transitoria). Esta anomalia personal provoca, en muchas ocasiones, una disminución del disfrute de los derechos y, en este sentido, las políticas públicas deben tender a solucionar en el mayor grado posible dicha anomalía, integrando a la persona".
} 
Não obstante a capacidade civil fosse considerada regra e a incapacidade civil uma hipótese excepcional, a declaração de incapacidade transferia a tomada de decisões patrimoniais e existenciais da pessoa com deficiência "interditada" ao "curador".

Apesar do movimento de repersonalização das categorias do direito civil a partir da leitura sistemática pelas lentes da unidade da Constituição Federal de 1988, o Código Civil de 2002 continuou a prever a hipótese de incapacidade absoluta da pessoa com deficiência em lógica ainda voltada a um modelo médico, pois atribuía a referida classificação a quem fosse considerado "anormal" para a sociedade por um ponto de vista de ideal de saúde mental definido pelos manuais médicos. O artigo $3^{\circ}$, inciso II do Código Civil, categorizava como absolutamente incapazes os "que por enfermidade ou deficiência mental, não tiverem o necessário discernimento para a prática desses atos" e seu artigo $4^{\circ}$, incisos II e III, classificava como "relativamente incapazes" aqueles "que, por deficiência mental, tenham o discernimento reduzido" (artigo $4^{\circ}$, inciso II) e "os excepcionais, sem desenvolvimento mental completo".

Em sua redação original, o Código Civil de 2002 absorvia pela expressão "absolutamente incapaz" o contingente de pessoas com deficiência psíquica ou intelectual com a mais diversa gama de discernimento e potencialidades. Anderson Schreiber e Ana Luiza Maia Nevares (2016, p. 41) tecem crítica a respeito da lógica de "tudo ou nada" imperante na legislação, já que a pessoa assim declarada em juízo o seria para todos os atos da vida civil, fossem eles de viés patrimonial, fossem existenciais.

A interdição e declaração de incapacidade absoluta obstavam a liberdade de escolha não somente para atos patrimoniais, mas também para atos existenciais, pois o regime da curatela se pautava em paradigma de substituição da vontade. ${ }^{4}$

Nesse trilhar, a garantia dos direitos da personalidade são encobertos pela ênfase à proteção patrimonial e se contrapõem ao regime clássico das incapacidades. Essa flagrante fratura que acompanha a crítica ao sistema de incapacidade da pessoa com deficiência também encontra subsídio em situações que envolvem alguns casos concretos difíceis de serem examinados sob olhar estritamente patrimonial.

A título ilustrativo, recorda-se de situação julgada em 2005 pelo Conselho Regional de Medicina no Ceará em que uma adolescente relativamente incapaz se recusou a amputar sua perna, de forma contrária à vontade de seus pais e assistentes, como tratamento de saúde à osteossarcoma de fêmur (LIMA; MENEZES, 2014). Outra fissura do sistema patrimonial de direito civil refere-se ao caso de pessoas transgêneras que desejam alterar o prenome e designativo de gênero no registro civil, contudo têm o resguardo de seu direito ao nome tolhido por justificativa dos tribunais de colisão com o princípio da "segurança jurídica". ${ }^{5}$

Cabe frisar que mesmo pessoas consideradas capazes pelo ordenamento jurídico brasileiro acabam por ter sua liberdade cerceada através do mecanismo da interdição. Cita-se o polêmico caso de rapaz maior de idade do estado de Goiás que se negou a continuar com sessões semanais de hemodiálise, diante do sofrimento e redução de qualidade de vida que lhe causavam. Sua mãe buscou a tutela jurisdicional para declarar a incapacidade do filho e se tornar sua curadora, o que foi autorizado em sentença da $2^{\mathrm{a}}$ Vara Cível da comarca de Trindade ao final de 2017 (TOMAZELA, 2017).

\footnotetext{
Amita Dhanda (2007, p. 429-462) identifica três enfoques de compreensão da capacidade da pessoa com deficiência psíquica ou intelectual pelos ordenamentos jurídicos de matriz ocidental: o enfoque do status (status approach), o enfoque do resultado ou da substituição da vontade (outcome approach) e o enfoque funcional (functional approach). O primeiro é observado em legislações que atribuem a incapacidade absoluta diretamente a quem se considerar "pessoa com deficiência", sem que se perscrute sua capacidade mental de discernir o contexto em que vive. O segundo remete à perspectiva referida no sistema clássico do direito civil brasileiro e na redação original do Código Civil atualmente vigente no país, por compreender que algumas pessoas não possuem discernimento para tomar decisões sobre sua vida e patrimônio por si mesmas e, portanto, uma terceira pessoa o deveria fazer. Esses dois paradigmas se comunicam diretamente ao modelo médico de encarar a deficiência. Por outro lado, o paradigma funcional dialoga com o modelo social da deficiência, pois fornece mecanismos de apoio à tomada de decisões pela própria pessoa com deficiência, na medida da individualidade de suas potencialidades. Esse último enfoque é o depreendido da redação da Convenção sobre os Direitos das Pessoas com Deficiência.

5 Em acórdão de 2014, o Tribunal de Justiça do estado do Paraná julgou recurso de Apelação em face de sentença que julgou improcedente o pedido da autora de retificar seu prenome e designativo de gênero em ação de retificação de registro civil. Em suas razões de recurso, a apelante explicou sua condição transgênera, apesar de não diagnosticada por médico. O acórdão negou provimento ao apelo e estruturou sua argumentação em observações quanto ao "transexualismo" como patologia que desemboca na rejeição dos órgãos sexuais (PARANÁ. TJPR, 2014).
} 
Esses quadros situam a intricada discussão sobre a incapacidade e seu uso como instrumento que solapa direitos da personalidade. Atos de decisão como "com quem morar", "com quem casar" e "com que se relacionar" são embaraçados por terceiros que, amparados pelo Direito, tradicionalmente decidiam por pessoas com deficiência psíquica ou intelectual consideradas absolutamente incapazes.

Relembra-se que, no contexto do Código Civil de $1916,{ }^{6}$ a pessoa com deficiência sob curatela só poderia se casar com o consentimento de seu curador, ou com seu suprimento em juízo, sob pena de impedimento matrimonial. Além disso, já na vigência da redação original do Código Civil de 2002, os curadores da pessoa com deficiência "interditada" poderiam revogar a autorização para o casamento até a data de sua celebração. ${ }^{7}$

Situações de vulnerabilidade demandam, de fato, respostas de viés protetivo, porém elas não bastam. Deve-se compreender a igualdade em plano de garantia do exercício da capacidade legal e consequente fortalecimento de direitos humanos e fundamentais. Pelo ponto de vista da teoria crítica dos direitos humanos, estes não podem ser reduzidos a um patamar abstrato, em que a sua mera enunciação em tratados internacionais ou documentos legislativos é suficiente para sua efetividade. ${ }^{8}$

Desse modo, é preciso conjugar a proteção da pessoa com deficiência à emancipação e à liberdade substantiva em atuação prospectiva do Direito, a qual, de acordo com Luiz Edson Fachin (2015, p. 86), "é a atuação hermenêutica da reconstrução permanente, correta e adequada, dos significados que se aplicam aos significantes que integram a teoria e a prática do Direito Civil". O sentido de capacidade legal, descortinado pela Convenção de Nova lorque, parece contribuir para a dignidade e reconhecimento dos direitos da personalidade e de constituição de entidades familiares por pessoas com deficiência.

\section{A capacidade legal e escolhas existenciais: a lógica da Convenção de Nova lorque}

A tutela dos direitos da personalidade e da decisões de índole personalíssima foram enfatizadas na Convenção sobre os Direitos das Pessoas com Deficiência. Com o fim de dar voz ao grupo vulnerável em todas as frentes de relações vivenciadas, o referido tratado internacional se vincula à ideia do modelo social e ao enfoque funcional da capacidade legal.

O modelo social nasceu nos anos 1960, no Reino Unido, imbricado ao "Social Disability Movement", movimento de luta pelo rompimento com o modelo médico de concepção da deficiência como um desvio da "normalidade" e a compreende em prisma de relação entre a existência individual de cada um com as barreiras encontradas em sociedade. Segundo Débora Diniz e Marcelo Medeiros (2004, p. 108), o modelo social enxerga a deficiência como uma "experiência resultante da interação entre características corporais do indivíduo e as condições da sociedade em que ele vive".

O referido pensamento é compatível ao sistema funcional (functional approach) da capacidade legal, pois se ancora no desenvolvimento de instrumentos de apoio moldados às potencialidades da pessoa com deficiência para tomar decisões, tanto no plano patrimonial quanto existencial. Os incisos 3 e 4 do artigo 12 da Convenção de Nova lorque são transparentes à opção e estímulo da adoção desse modelo pelos países signatários:

Artigo 12. Reconhecimento igual perante a lei [...] 3.Os Estados Partes tomarão medidas apropriadas para prover o acesso de pessoas com deficiência ao apoio que necessitarem no exercício de sua capacidade legal.

6 “Art. 183. Não podem casar (arts. 207 e 209): [...] XI. Os sujeitos ao pátrio poder, tutela, ou curatela, enquanto não obtiverem, ou lhes não for suprido o consentimento do pai, tutor, ou curador (art. 211)".

"Art. 1.518. Até a celebração do casamento podem os pais, tutores ou curadores revogar a autorização. (Redação revogada pelo Estatuto da Pessoa com Deficiência)".

8 Nas palavras de David Sánchez Rúbio (2014, p. 129-130): “Está fora de qualquer dúvida a necessidade das dimensões filosóficas, jurídicopositivas e de eficácia estatal. São conquistas humanas que têm de se consolidar e reforçar, sem cair em eurocentrismos ou ocidentalismos, mas não são estas as únicas e exclusivas formas de garantia contra os diferentes excessos de poder. São necessárias, porém insuficientes, por muitas razões. Está clara a necessidade de melhorar e fortalecer o papel do direito e dos sistemas de proteção dos direitos humanos tanto em nível nacional como internacional, assim como é imprescindível reconhecê-los institucionalmente, mas não há que se dar para esta dimensão normativa o protagonismo único e exclusivo". 
4.Os Estados Partes assegurarão que todas as medidas relativas ao exercício da capacidade legal incluam salvaguardas apropriadas e efetivas para prevenir abusos, em conformidade com o direito internacional dos direitos humanos. Essas salvaguardas assegurarão que as medidas relativas ao exercício da capacidade legal respeitem os direitos, a vontade e as preferências da pessoa, sejam isentas de conflito de interesses e de influência indevida, sejam proporcionais e apropriadas às circunstâncias da pessoa, se apliquem pelo período mais curto possível e sejam submetidas à revisão regular por uma autoridade ou órgão judiciário competente, independente e imparcial. As salvaguardas serão proporcionais ao grau em que tais medidas afetarem os direitos e interesses da pessoa. [...].

As salvaguardas a que o dispositivo se refere têm por função dosar a proteção direcionada à pessoa com deficiência, em harmonização da garantia de liberdade individual e proteção à sua condição de vulnerabilidade.

A lógica imperante no tratado internacional é a de proteger até mesmo o "direito de errar" (CONCIL OF EUROPE, 2012, p. 12). Prevaleceu na redação da Convenção um conceito conglobante de capacidade legal (ARAUJO; RUZYK, 2017, p. 233) que abrange os sentidos clássicos de capacidade de direito e de capacidade de exercício de modo unificado, ao lado de um sistema de apoios que não destitua o poder de decisão da própria pessoa com deficiência. Em meio à elaboração do texto do tratado, a ONG “World Network of Users and Survivors of Psychiatry" emitiu parecer posicionando-se favorável a essa perspectiva:

Persons with disabilities have the right to make decisions based on their own feelings and values, and to not have their decisions interfered with by others. This is what is meant by a right to autonomy and self-determination. [...] Such needs for assistance do not make the person incapable of making a decision, and do not justify taking away the person's right to make his or her own decision. ${ }^{9}$

A independência e liberdade de escolha sobre com quem e onde viver são importantes direitos guarnecidos pela Convenção, que deles tratou nos artigos $19^{10} \mathrm{e}$ artigo $23 .{ }^{11}$ Essa proteção é marcante, especialmente por conta da expressiva institucionalização da pessoa com deficiência psíquica em ambientes que, por vezes, acabam por extinguir sua individualidade. Deve-se lembrar que o primeiro caso de condenação do estado brasileiro pela Corte Interamericana de Direitos Humanos decorreu de agressões físicas seguidas de morte de Damião Ximenes Lopes enquanto estava internado em clínica psiquiátrica no estado do Ceará (CORTE INTERAMERICANA DE DIREITOS HUMANOS, 2006).

Para além da proteção da escolha de onde viver em contraposição à institucionalização da pessoa com deficiência, a Convenção também resguarda o direito de constituir família, bem como seus direitos sexuais e reprodutivos (artigo 23).

Apesar de esses direitos serem fundamentais e se cogitar sua aplicabilidade imediata por controle de convencionalidade, somente meia década após a internalização da Convenção ao direito brasileiro, com status material e formal de Emenda à Constituição ${ }^{12}$, é que houve a promulgação da Lei Brasileira de Inclusão, ou Estatuto da Pessoa com Deficiência (doravante "EPD") - Lei n. 13.146/2015 - na tentativa de adequar a legislação interna ao paradigma da Convenção e dar efetividade aos direitos por ela enunciados.

9 Em tradução livre: "Pessoas com deficiência têm o direito de tomar decisões baseadas em seus próprios sentimentos e valores, e não ter suas decisões interferidas por outros. Isso é o que se quer dizer quando se trata do direito à autonomia e auto-determinação. [...] Necessidades por assistência não fazem essa pessoa incapaz de tomar uma decisão, e não justificam destituir uma pessoa do direito de tomar suas próprias decisões." (ONU, 2004).

10 "Artigo 19. Vida independente e inclusão na comunidade. Os Estados Partes desta Convenção reconhecem o igual direito de todas as pessoas com deficiência de viver na comunidade, com a mesma liberdade de escolha que as demais pessoas, e tomarão medidas efetivas e apropriadas para facilitar às pessoas com deficiência o pleno gozo desse direito e sua plena inclusão e participação na comunidade, inclusive assegurando que: a) As pessoas com deficiência possam escolher seu local de residência e onde e com quem morar, em igualdade de oportunidades com as demais pessoas, e que não sejam obrigadas a viver em determinado tipo de moradia; [...]".

11 "Artigo 23. Respeito pelo lar e pela família 1.Os Estados Partes tomarão medidas efetivas e apropriadas para eliminar a discriminação contra pessoas com deficiência, em todos os aspectos relativos a casamento, família, paternidade e relacionamentos, em igualdade de condições com as demais pessoas, de modo a assegurar que: a) Seja reconhecido o direito das pessoas com deficiência, em idade de contrair matrimônio, de casar-se e estabelecer família, com base no livre e pleno consentimento dos pretendentes; [...]".

12 A assinatura do tratado se deu em 30/03/2007 e sua ratificação ocorreu em 2008 pelo Congresso Nacional seguindo-se o procedimento previsto no art. $5^{\circ}, \S 3^{\circ}$ da Constituição Federal. Não se olvida do tema do "controle de Convencionalidade" das normas internas do direito brasileiro, a respeito do qual Flávia Piovesan (2012, p. 91) destaca que a proteção dos direitos humanos (human rights approach) constitui o ápice do sistema internacional e que o "controle de convencionalidade" é importante instrumento para a concretização de medidas protetivas aos direitos humanos constantes de tratados internacionais. 
Flagrante, nesse cenário, a tensão entre a garantia de direitos positivados em tratado internacional visando à proteção de um grupo vulnerável e os obstáculos formais e materiais colocados à frente da eficácia concreta desses enunciados. Do ponto de vista de Joaquín Herrera Flores (2009), o "direito dos direitos humanos" está além da sua formalidade e não funciona por si mesmo, pois exige uma postura, tanto vertical quanto horizontal, de reafirmação desses direitos no dia a dia e por diversos agentes:

O direito não vai surgir, nem funcionar, por si só. As normas jurídicas poderão cumprir uma função mais em concordância com o 'que ocorre em nossas realidades' se as colocarmos em funcionamento - a partir de cima, mas sobretudo a partir de baixo -, assumindo desde o princípio uma perspectiva contextual e crítica, quer dizer, emancipadora (FLORES, 2009, p. 18).

Não se descarta a importância da norma positivada para o processo de afirmação de direitos das pessoas com deficiência, contudo, sublinha-se, não é o bastante.

Por exemplo, nota-se que o direito à liberdade e independência para tomar decisões referentes a direitos da personalidade e sobre a constituição de entidade familiar em conjugalidade foi positivada pelo EPD de modo harmônico ao previsto abstratamente na Convenção de Nova lorque, por meio da redação de seu artigo 6०: "A deficiência não afeta a plena capacidade civil da pessoa, inclusive para: I - casar-se e constituir união estável; [...]".

Contudo, sob perspectiva crítica, não se pode limitar a análise da garantia de decisões da pessoa com deficiência a questões existenciais, ou dirigidas à construção da vida, que se valorizam para si à redação desse artigo. É indispensável perquirir as demandas das pessoas a quem a norma pretende proteger para dar espaço à fruição das situações previstas.

\section{Sistema de apoios e o direito à escolha de com quem se casar}

A decisão de pessoas com deficiência sobre com quem viver em conjugalidade pela via do casamento civil robustece o debate ora proposto. A Associação "Reviver Down" relata que pessoas com síndrome de Down que frequentam suas instalações na cidade de Curitiba, há muitos casais de namorados, contudo, poucos pensam em se casar. Ao ver da presidente da associação, as famílias criam barreiras para a independência dos filhos com síndrome de Down, que optam por não viver sua relação afetiva sob as vestes do casamento (CARVALHO, 2017).

A lógica de resguardo da escolha de formar família matrimonial entre pessoas com deficiência representa uma quebra de paradigmas antes sequer questionados pelo Direito, dado que o sistema jurídico clássico trazia obstáculos formais ao casamento por pessoas com deficiência.

De acordo com a redação original do Código Civil de 2002, a exemplo do diploma anterior, a pessoa com deficiência submetida à curatela só poderia se casar com a autorização de seu curador, de modo que uma escolha atinente à existência e personalidade da pessoa acabava por ser subordinada ao juízo de quem a assistia ou a representava para os atos da vida civil. Retoma-se, neste ponto, a fissura representada pelo regime das incapacidades que, sob a justificativa de proteção do patrimônio da pessoa com deficiência, ao fim e ao cabo, contribuía para a aniquilação de sua vontade e liberdade de escolha também em âmbito extrapatrimonial.

Esse cenário, ao menos de um ponto de vista formal, foi alterado pelas mudanças engendradas pela Convenção de Nova lorque e legislações internas que a seguiram, dentre as quais se destaca o já citado EPD. Não obstante tenha sido propugnada a prevalência de um sentido conglobante de "capacidade legal", verifica-se a complexidade de dar-Ihe efetividade no Direito brasileiro, já que até mesmo a doutrina pátria não é uníssona.

Contrária ao conceito conglobante de capacidade legal, Regina Beatriz Tavares (2017) lê o artigo 12 da Convenção de modo restrito à capacidade de direito e afirma que a perspectiva "que considera o deficiente mental, a partir da vigência do EPD, plenamente capaz para a prática de todos os atos da vida civil, é um grave e perigoso equívoco". Na mesma linha de raciocínio, José Fernando Simão concebe a 
redação do Código Civil brasileiro nos moldes anteriores ao tratado internacional como mais protetiva ao grupo vulnerável (SIMÃO, 2015).

Não só a doutrina apresenta essa resistência ao novo paradigma de capacidade legal, como também tramita o Projeto de Lei do Senado n. 757, proposto em dezembro de 2015 pelos senadores Paulo Paim (PT-RS) e Antonio Carlos Valadares (PSB-SE), que visa à alteração do Código Civil e do EPD (BRASIL, 2015). O atual texto do consiste em redação substitutiva do parlamentar Telmário Mota (PDT-RO) e está sob exame da Comissão de Constituição, Justiça e Cidadania da referida Casa Legislativa. Uma das alterações indicadas é retomar as categorias de incapacidade absoluta e relativa para pessoas sem o necessário discernimento para a prática de atos civis ou com "discernimento severamente reduzido".

Flávio Tartuce apresentou parecer sobre o PLS e concordou com essas propostas, afirmando que as pessoas incapazes mentalmente de exprimir sua vontade "ficam abandonadas à própria sorte" diante da "capacidade legal" (TARTUCE, 2016, p. 05).

Em sentido convergente ao tratado está o parecer de Joyceane Bezerra de Menezes sobre o projeto de lei, feito a pedido Instituto Brasileiro de Direito de Família (IBDFam). A parecerista ressalta que o trâmite do projeto não foi acompanhado de um diálogo com os principais destinatários da norma e confronta o lema "Nada sobre nós, sem nós". A seu ver, o conteúdo se apresenta como um "risco de retrocesso" à noção de capacidade legal. ${ }^{13}$

O PLS n. 757 não tem previsão de se converter em lei, mas é indicativo do complexo debate em torno dos significantes atribuídos ao exercício de direitos fundamentais de sujeitos vulnerados.

A presente pesquisa se alinha à interpretação de ampliação de liberdades da pessoa com deficiência como regra a ser priorizada, sem que haja substituição de sua vontade ou desrespeito às suas preferências, principalmente em âmbito existencial.

Neste passo, algumas considerações devem ser ressaltadas quando se enfrenta a temática da decisão de caráter extrapatrimonial de formar família pelo casamento.

A Convenção preconiza o atendimento às preferências da pessoa com deficiência psíquica ou intelectual e observa suas potencialidades para exercício de sua liberdade substancial. Contudo, há casos extremos que exigem uma leitura excepcional, tais como o quadro concernente à pessoa com deficiência, que não possui meios para exteriorizar a sua vontade, e o casamento como intensificação de sua vulnerabilidade, ou até mesmo um quadro de violência e abuso.

Em uma situação excepcional como esta, parte da doutrina brasileira atual propõe a releitura da Teoria da Inexistência, desenvolvida por Pontes de Miranda (2012, p. 192), segundo o qual um ato jurídico praticado por pessoa absolutamente incapaz seria nulo pela falta de manifestação da vontade.

A aludida teoria é lida à luz da Convenção de Nova lorque, interpretando-se o "absolutamente incapaz" como a pessoa com deficiência impossibilitada de manifestar sua vontade, ainda que com sua capacidade legal reconhecida. Segundo Zeno Veloso (2016) , o uso da Escala Ponteana para interpretação de negócios jurídicos praticados por pessoas com deficiência capaz, porém sem discernimento, pode evitar a desproteção do vulnerável:

Um deficiente mental, que tem comprometido absolutamente o seu discernimento, ou que sofre de insanidade permanente, irreversível, é considerado relativamente incapaz. Bem como o que manifestou a sua vontade quando estava em estado de coma. Ou o que contratou, ou perfilhou, ou fez testamento, sendo portador do mal de Alzheimer em grau extremo. São casos em que não me parece que essas pessoas estejam sendo protegidas, mas, ao contrário, estão à mercê da sanha dos malfeitores, podendo sofrer consideráveis e até irremediáveis prejuízos. [...] Na falta de uma

13 "Nesse aspecto, o PLS n 757/2015 representa uma certa ameaça ao teor da Convenção, ainda que o objetivo dos seus proponentes tenha sido o de proteger a pessoa com deficiência. Importa observar que, sob a perspectiva do sistema protetivo-emancipatório instituído pela Convenção, a proteção da pessoa com deficiência pode ser feita por meio de apoio e salvaguardas, e não pela restrição prévia da sua autonomia. Se houver necessidade de ajustes ao EPD, que estes sejam feitos em harmonia com a CDPD e os demais valores fundamentais do sistema jurídico consignados nas normas constitucionais." (MENEZES, 2017, p. 141). 
intervenção corretiva do legislador (que sempre é tardonha), minha primeira impressão sobre a questão que estou apresentando, é de que, para evitar graves distorções e evidentes injustiças, temos de invocar a teoria da inexistência, e privar de qualquer efeito negócios jurídicos cuja vontade foi extorquida e nem mesmo manifestada conscientemente.

Por esse prisma, o casamento de uma pessoa com deficiência que não tenha discernimento para expressar sua vontade - tal como pessoa com paralisia cerebral - seria considerado inexistente em razão de não possuir elemento constitutivo, no caso, a vontade (conforme o ditame do artigo 1.514 do Código Civil: "O casamento se realiza no momento em que o homem e a mulher manifestam, perante o juiz, a sua vontade de estabelecer vínculo conjugal, e o juiz os declara casados."). Logo, por não ser constatada vontade de um ou de ambos os nubentes, o casamento não se perfaz e é considerado inexistente.

É dado tratamento diverso, portanto, ao que constava do revogado artigo 1.548, inciso I, do Código Civil, que tratava de hipótese de nulidade do casamento, pois se refere ao Plano da Validade do negócio jurídico. Desse modo, de acordo com a Teoria da Inexistência, a lei não poder prever prazo para sua arguição, já que se trata do "nada" (nihil est).

Joyceane Bezerra de Menezes (2018) sugere que é possível, em uma lógica contemporânea, aliando interpretação analógica do art. 46 da Resolução $n^{\circ} 35$ do Conselho Nacional de Justiça ${ }^{14}$, que o oficial de registro tem a prerrogativa de recusar o requerimento para o matrimônio formulado por pessoa com deficiência severa em caso de dúvida sobre a sua declaração de vontade. Segundo a autora:

[o oficial] Não estaria agindo em discriminação porque houve dúvida em relação à declaração de vontade, dado que também pode ocorrer nos processos que envolvem pessoa sem deficiência. Poderia também, apenas suscitar a dúvida ao juiz de família que, mediante a oitiva do representante do Ministério Público, decidirá (MENEZES, 2018).

Por outro lado, quando se trata de pessoa com deficiência com algum discernimento e que não suscite dúvidas à declaração de vontade, menciona-se o trabalho de Eduardo Nunes de Souza e Rodrigo da Guia Silva (2016, p. 08), que sugere, à luz do direito civil-constitucional, uma "modulação do regime legal da nulidade e da anulabilidade por força de uma concreta valoração dos efeitos negociais, fundamentadamente, sempre que a disciplina prevista para o tipo de invalidade não promover, do modo mais adequado, os valores do ordenamento". Em outras palavras, os autores defendem uma avaliação funcional do ato jurídico no plano das validades que seja condizente ao merecimento de tutela dos interesses dos vulneráveis envolvidos.

Conforme preceitua o artigo 85 do Estatuto da Pessoa com Deficiência, atos existenciais não são, em regra, submetidos à curatela, entretanto também demandam leitura funcional sobre seu plano da validade - quando não também do plano de existência- caso se observe concretamente a contrariedade à própria liberdade e dignidade da pessoa com deficiência.

Logo, a depender do grau de discernimento da pessoa com deficiência para compreender as condições que envolvem uma escolha extrapatrimonial, como é a de se casar, pode ser cumulada a nulidade ou a anulabilidade.

O prazo para anulação do casamento celebrado por pessoa incapaz de consentir ou manifestar seu consentimento consta do artigo 1.560, inciso I, do Código Civil, é de 180 dias e é contado a partir da data de sua celebração.

Ressalvadas as hipóteses excepcionais em que não subsista condição de vulnerabilidade que justifique a anulação ou nulidade, é imperativa a proteção dos efeitos jurídicos da decisão pela vida em conjugalidade e independência da pessoa que assim optou.

No direito brasileiro, após o Estatuto da Pessoa com Deficiência, a escolha por viver em conjugalidade não depende da autorização, ou substituição da vontade por curador. Por outro lado, o instrumento da Tomada de Decisão Apoiada (regulado pelo artigo 1.783-A do Código Civil e incluído pelo EPD) poderia ser

14 "Art. 46. O tabelião poderá se negar a lavrar a escritura de separação ou divórcio se houver fundados indícios de prejuízo a um dos cônjuges ou em caso de dúvidas sobre a declaração de vontade, fundamentando a recusa por escrito". (BRASIL. CNJ, 2007). 
utilizado para ampliar a liberdade substantiva da pessoa com deficiência capaz, mas que demanda algum tipo de apoio para compreender o contexto de uma situação que exige sua escolha:

Art. 1.783-A. A tomada de decisão apoiada é o processo pelo qual a pessoa com deficiência elege pelo menos 2 (duas) pessoas idôneas, com as quais mantenha vínculos e que gozem de sua confiança, para prestar-Ihe apoio na tomada de decisão sobre atos da vida civil, fornecendo-lhes os elementos e informações necessários para que possa exercer sua capacidade.

A função e finalidade da Tomada de Decisão Apoiada desperta discussões doutrinárias, dentre elas a que gira em torno da sua (im)prescindibilidade para a realização exclusivamente de atos patrimoniais, e a discussão sobre a referência a "atos civis" também abarca atos extrapatrimoniais, como o casamento.

Está em jogo a compreensão sobre a vontade livre da pessoa com deficiência em escolher com quem viver, sem que isso origine uma situação abusiva. Eis o grande desafio situado na temática: tutelar a escolha pela vida independente e desvinculada de um enfoque substitutivo da vontade, ao mesmo tempo em que sejam protegidos os interesses da pessoa com deficiência psíquica ou intelectual.

A título ilustrativo da complexidade que envolve a temática do casamento por pessoa com deficiência e os desafios da adequação do novo paradigma da capacidade legal, menciona-se caso julgado em 2016 pelo Tribunal de Justiça do Rio Grande do Sul.

O senhor M.G.S., submetido à curatela após processo de interdição sob a vigência da redação original do Código Civil de 2002, ajuizou ação requerendo a autorização judicial para se casar, uma vez que seu curador não concordara com seu desejo. Em primeiro grau de jurisdição, seu pedido foi julgado improcedente sob o fundamento de impedimento para o casamento diante de sua incapacidade absoluta para realização de atos da vida civil. O Tribunal reformou a sentença, salientando a revogação do artigo 1.548, inciso I, do Código Civil e a consequente nulidade de casamento por pessoa com deficiência mental, autorizando, assim, a habilitação do recorrente para o matrimônio. O acórdão transcreve interessante trecho do parecer da Procuradoria Geral de Justiça, ora reproduzido em parte:

[...] com o advento da Lei $\mathrm{n}^{\circ} 13.146 / 2015$, o art. 1.548, inciso I, do Código Civil revogou-se, e não mais nulo é o casamento contraído 'pelo enfermo mental sem o necessário discernimento para os atos da vida civil.'A partir deste marco de explicitude legal não há reconhecimento pleno, total e absoluto de incapacidade da pessoa, não se embargam todos os atos da vida civil, senão apenas para alguns atos da vida civil, ou seja, a interdição há de ter limites plausíveis. (RIO GRANDE DO SUL. TJRS, 2016).

A ilustração demonstra a preocupação do julgador em dar efetividade ao contido no Estatuto da Pessoa com Deficiência quanto à limitação da curatela a atos patrimoniais, bem como à tutela das escolhas existenciais. Visualizam-se traços de uma aplicação prospectiva do previsto de modo abstrato no sentido formal e substancial do Direito atual.

Os casos exemplificados reforçam a afirmação de que há longo trajeto a ser percorrido para a materialização dos enunciados normativos de maior liberdade e reguardo de decisões legítimas da pessoa com deficiência perante o Estado, sociedade e família. Em trabalho pretérito desta autoria, afirmou-se que é insuficiente confiar a essa tríade de agentes a proteção e emancipação da pessoa com deficiência (MATOS; OLIVEIRA, 2016, p. 27).

Isso se reitera nesta oportunidade: ainda que imprescindível a previsão normativa de garantia de capacidade legal às pessoas com deficiência, psíquica ou intelectual, é igualmente necessário deitar os olhos às suas potencialidades concretas em fazer escolhas que constituem sua própria subjetividade, tais como com quem viver em conjugalidade.

\section{Conclusão}

Avanços e retrocessos constituem a dinâmica cardial de reconhecimento e afirmação de direitos humanos e fundamentais de grupos vulneráveis. As pessoas com deficiência não encontram cenário distinto. 
O conceito de capacidade legal abalizado na Convenção de Nova lorque propõe significativa releitura da disciplina da capacidade civil.

O regime clássico das incapacidades foi erigido com base na proteção do "ter" e não do "ser" e, ao revés, fomentou cenários de opressão a escolhas existenciais. Embora seja construído no plano formal o reconhecimento da decisão da pessoa com deficiência em viver com quem deseja em conjugalidade, notam-se óbices concretos, até mesmo em conceber a sua plena capacidade de exercício.

Esses obstáculos se encontram nas dissonâncias de interpretação da norma internacional e também na ausência de diálogo com seus destinatários para reformas legislativas que se apresentam como riscos de retrocessos ao que parcamente se instituiu.

Dentre essas reformas, a proposta do PLS n. 757/2015 embate a definição de capacidade legal da Convenção e divide opiniões entre a doutrina, como foi possível depreender do posicionamento de Flávio Tartuce e de Joyceane Bezerra de Menezes em seus respectivos pareceres.

Não é possível retroceder a ponto de retomar uma noção de incapacidade e, em casos extremos, de falta de discernimento de pessoas com deficiência. A doutrina constrói aos poucos leituras alternativas da dogmática, como fazer uso da teoria da inexistência desenvolvida pelo jurista Pontes de Miranda.

Além do mais, estudos teóricos atribuem renovado sentido para disciplinas clássicas, como o trabalho de Eduardo Nunes de Souza e Rodrigo da Guia Silva, que indica a modulação dos regimes da nulidade e da anulabilidade de modo funcional e leva em conta o juízo de tutela de interesses de vulneráveis que praticaram o ato jurídico.

O trabalho, portanto, procurou retratar os movimentos que constituem o quadro atual de luta constante pela efetivação de direitos de pessoas com deficiência, não apenas numa perspectiva patrimonial, mas, principalmente, numa linha de direitos existenciais.

\section{Referências}

AMARAL, Francisco. Direito civil: introdução. 6. ed. Rio de Janeiro: Renovar, 2006.

ARAUJO, Luiz Alberto David; RUZYK, Carlos Eduardo Pianovski. A perícia multidisciplinar no processo de curatela e o aparente conflito entre o estatuto da pessoa com deficiência e o código de processo civil: reflexões metodológicas à luz da teoria geral do direito. Revista de direitos e garantias fundamentais, Vitória, v. 18, n. 1, jan./abr. 2017. Disponível em: <http://sisbib.fdv.br/index.php/direitosegarantias/article/ viewFile/867/330>. Acesso em: 18 dez. 2017.

BRASIL. Senado Federal. Projeto de lei $\mathbf{n}^{\circ} \mathbf{7 5 7}$, de 2015. Autores: Senador Antonio Carlos Valadares (PSB/SE), Senador Paulo Paim (PT/RS). Senado Federal, Brasília, DF, 2015. Disponível em: <https:// www25.senado.leg.br/web/atividade/materias/-/materia/124251>. Acesso em: 12 jan. 2018.

BUTLER, Judith. Quadros de guerra: quando a vida é passível de luto? Rio de Janeiro: Civilização Brasileira, 2015.

CARVALHO, Marlene Dias. Casamento de pessoas com síndrome de Down. Entrevista por correio eletrônico <mdiasc@terra.com.br> em 07 dez. 2017.

NOTA da ABNT 6023 - As mensagens que circulam por intermédio do correio eletrônico devem ser referenciadas somente quando não se dispuser de nenhuma outra fonte para abordar o assunto em discussão. Mensagens trocadas por e-mail têm caráter informal, interpessoal e efêmero, e desaparecem rapidamente, não sendo recomendável seu uso como fonte científica ou técnica de pesquisa.

CONCIL OF EUROPE. Who gets to decide? Right to legal capacity for persons with intellectual and psychosocial disabilities. 2012. p. 12. Disponível em: <https://wcd.coe.int/ViewDoc. jsp?p=\&id=1908555\&direct=true >. Acesso em: 17 dez. 2017.

BRASIL. Conselho Nacional de Justiça (CNJ). Resolução n. 35, de 24 de abril de 2007. Disponível em: < http://www.cnj.jus.br/images/stories/docs_cnj/resolucao/rescnj_35.pdf >. Acesso em: 28 fev. 2018. 
CORTE INTERAMERICANA DE DIREITOS HUMANOS. Caso Ximenes Lopes versus Brasil. Sentença de 04 de julho de 2006. Disponível em: <http://www.corteidh.or.cr/docs/casos/articulos/seriec_149_por. pdf>. Acesso em: 18 dez. 2017.

DHANDA, Amita. Legal capacity in the disability rights Convention: stranglehold of the past or lodestar for the future? Syracuse Journal of International Law \& Commerce, Nova lorque, v. 34, p. 429-462, 2007.

FACHIN, Luiz Edson. Direito civil: sentidos, transformações e fim. Rio de Janeiro: Renovar, 2015.

FLORES, Joaquín Herrera. A (re)invenção dos direitos humanos. Trad. Jefferson Aparecido Dias, Carlos Roberto Diogo Garcia e Antônio Henrique Graciano Suxberger. Florianópolis: Fundação Boiteux, 2009.

INCLUSION INTERNATIONAL. Independiente pero no solo: Informe mundial sobre el derecho a decidir. Londres: University of East London. 2015. p. 71. Disponível em: <http://inclusion-international. org/wp-content/uploads/2014/06/independiente-pero-no-solo-web-rvsd1.2015.pdf>. Acesso em: 04 dez. 2017.

INSTITUTO BRASILEIRO DE GEOGRAFIA E ESTATÍSTICA (IBGE). Pesquisa Nacional de Saúde 2013: ciclos de vida. Rio de Janeiro: IBGE, 2017. v. 3. Disponível em: <https://biblioteca.ibge.gov.br/ visualizacao/livros/liv94522.pdf>. Acesso em: 04 dez. 2017.

LIMA, Luciana Vasconcelos; MENEZES, Joyceane Bezerra de. A autonomia para adolescentes em relação à recusa de tratamento médico. Publica direito. 2014. Disponível em: <http://www.publicadireito. com.br/artigos/?cod=e102943424a748e2>. Acesso em: 17 dez. 2017.

MATOS, Ana Carla Harmatiuk; OLIVEIRA, Ligia Ziggiotti de. Além da Convenção de Nova York: Além do estatuto da pessoa com deficiência - Reflexões a partir de uma compreensão crítica dos direitos humanos. Revista de derechos humanos y estúdios sociales - Redhes, Sevilha, ano VIII, n. 15, p. 15-32, jan./jun. 2016.

MEDEIROS, Marcelo; DINIZ, Debora. Envelhecimento e deficiência. In: CAMARANO, Ana Amélia (Org.). Os novos idosos brasileiros: muito além dos 60? Rio de Janeiro: IPEA, 2004. p. 107-120.

MENEZES, Joyceane Bezerra de. O risco do retrocesso: uma análise sobre a proposta de harmonização dos dispositivos do Código Civil, do CPC, do EPD e da CDPD a partir da alteração da Lei $n^{\circ} 13.146$, de 06 de julho de 2015. Revista Brasileira de Direito Civil - RBDCivil, Belo Horizonte, v. 12, p. 137-171, abr./ jun. 2017.

MENEZES, Joyceane Bezerra de. I Encuentro Internacional sobre los derechos de la persona com discapacidad en el Derecho Privado de España, Brasil, Italia y Portugal. Sevilha - Espanha, 29 e 30 jan. 2018. Palestra.

MIRANDA, Pontes de. Tratado de Direito Privado: validade, nulidade, anulabilidade. Atualizado por Marcos Bernardes de Mello e Marcos Ehrhardt Jr. São Paulo: Revista dos Tribunais, 2012. t. IV.

NABERGOI, Mariela; BOTINELLI, María Marcela. Discapacidad, pobreza y sus abordajes: Revisión de la estrategia de rehabilitación basada en la comunidad (RBC). Anu. Investig. Buenos Aires, v. 14 ene./dic. 2007. Disponível em: <http://www.scielo.org.ar/scielo.php?pid=S1851-16862007000100015\&script=sci_ arttext\&tlng=en>. Acesso em: 04 dez. 2017.

NEVARES, Ana Luiza Maia; SCHREIBER, Anderson. Do sujeito à pessoa: uma análise da incapacidade civil. In: TEPEDINO, Gustavo; TEIXEIRA, Ana Carolina Brochado; ALMEIDA, Vitor (Coord.). 0 direito civil entre o sujeito e a pessoa. Belo Horizonte: Fórum, 2016. p. 39-56.

\section{ORGANIZAÇÃO DAS NAÇÕES UNIDAS. Contribution by}

World Network of Users and Survivors of Psychiatry (WNUSP) - 2004. Disponível em: <http://www. un.org/esa/socdev/enable/rights/wgcontrib-wnusp.htm>. Acesso em: 18 dez. 2017.

ORGANIZAÇÃO DAS NAÇÕES UNIDAS. Disability and Sustainable Urban Development

(2016-A). Disponível em: <http://www.un.org/disabilities/documents/2016/Urban/

DESAissuepaperonAccessibilityandInclusionofPersonswithDisabilitiesinUrbanDevelopment.pdf $>$. Acesso em: 04 dez. 2017. 
ORGANIZAÇÃO DAS NAÇÕES UNIDAS. The invisibility of disability (2016-B). Disponível em: <http:// www.un.org/disabilities/documents/sdgs/infographic_statistics_2016.pdf >. Acesso em: 04 dez. 2017.

ORGANIZAÇÃO DAS NAÇÕES UNIDAS. Vigilancia del cumplimiento de la Convención sobre los

Derechos de las Personas con Discapacidad: Guía para los observadores de la situación de los derechos humanos (2010). Nova lorque e Genebra. Disponível em: <http://www.ohchr.org/Documents/ Publications/Disabilities_training_17_sp.pdf>. Acesso em: 04 dez. 2017.

PIOVESAN, Flávia. Direitos humanos e diálogo entre jurisdições. Revista Brasileira de Direito Constitucional - RBDC, São Paulo, n. 19, p. 67-93, jan./jun. 2012.

RÚBIO, David Sánchez. Encantos e desencantos dos direitos humanos: de emancipações, libertações e dominações. Porto Alegre: Livraria do Advogado, 2014.

SILVA, Rodrigo da Guia; SOUZA, Eduardo Nunes de. Autonomia, discernimento e vulnerabilidade: estudo sobre as invalidades negociais à luz do novo sistema das incapacidades. Civilistica.com., Rio de Janeiro, ano 5, n. 1, p. 8, 2016. Disponível em: <http://civilistica.com/autonomia-discernimento-evulnerabilidade/>. Acesso em: 18 dez. 2017.

SIMÃO, José Fernando. Estatuto da pessoa com deficiência causa perplexidade. Parte I. Conjur, São Paulo, 6 ago. 2015. Disponível em: <http://www.conjur.com.br/2015-ago-06/jose-simao-estatuto-pessoadeficiencia-causa-perplexidade>. Acesso em: 12 jan. 2018.

TARTUCE, Flávio. Parecer sobre o Projeto de Lei do Senado Federal n. 757/2015. Altera o Estatuto da Pessoa com deficiência, o Código Civil e o Código de Processo Civil, p. 05 Disponível em: <https:/l legis.senado.leg.br/sdleg-getter/documento?dm=4374546\&disposition=inline>. Acesso em: 12 jan. 2018.

TAVARES, Regina Beatriz. Certezas e incertezas após o primeiro ano de vigência do Estatuto da Pessoa com Deficiência. Estadão, São Paulo, 20 abr. 2017. Disponível em: <http://politica.estadao.com.br/ blogs/fausto-macedo/certezas-e-incertezas-apos-o-primeiro-ano-de-vigencia-do-epd-estatuto-da-pessoacom-deficiencia/>. Acesso em: 12 jan. 2018.

TOMAZELA, José Maria. Justiça determina interdição de jovem que recusa hemodiálise para morrer em Goiânia. Estadão, São Paulo, 28 nov. 2017. Disponível em: <http://saude.estadao.com. $\mathrm{br} /$ noticias/geral,justica-determina-interdicao-de-jovem-que-recusa-hemodialise-para-morrer-emgoiania,70002099942>. Acesso em: 03 dez. 2017.

PARANÁ. Tribunal de Justiça - TJ-PR. Apelação Cível 1.091.843-7. Relator: Des. Renato Lopes de Paiva, 11 ${ }^{\text {a }}$ Câmara Cível, julgado em 02/07/2014. Diário da Justiça, Brasília, DF, 25 jul. 2014.

RIO GRANDE DO SUL. Tribunal de Justiça - TJ-RS. Apelação Cível n. 70070435912. Relator: Des. Rui Portanova, Oitava Câmara Cível, julgado em 13/10/2016. Diário da Justiça, Brasília, DF, 18 out. 2016.

VELOSO, Zeno. Estatuto da pessoa com deficiência: uma nota crítica. Disponível em: < http://www. ibdfam.org.br/artigos/1111/Estatuto+da+Pessoa+Com+Defici\%C3\%AAncia-+uma+nota+cr\%C3\%ADtica>. Acesso em: 28 nov. 2017.

WORLD HEALTH ORGANIZATION. World report on disability 2011. Disponível em: <http://www. pessoacomdeficiencia.sp.gov.br/usr/share/documents/relatorio_mundial_completo.pdf>. Acesso em: 17 dez. 2017.

Recebido em: 28/02/2018

Aprovado em: 19/05/2018 